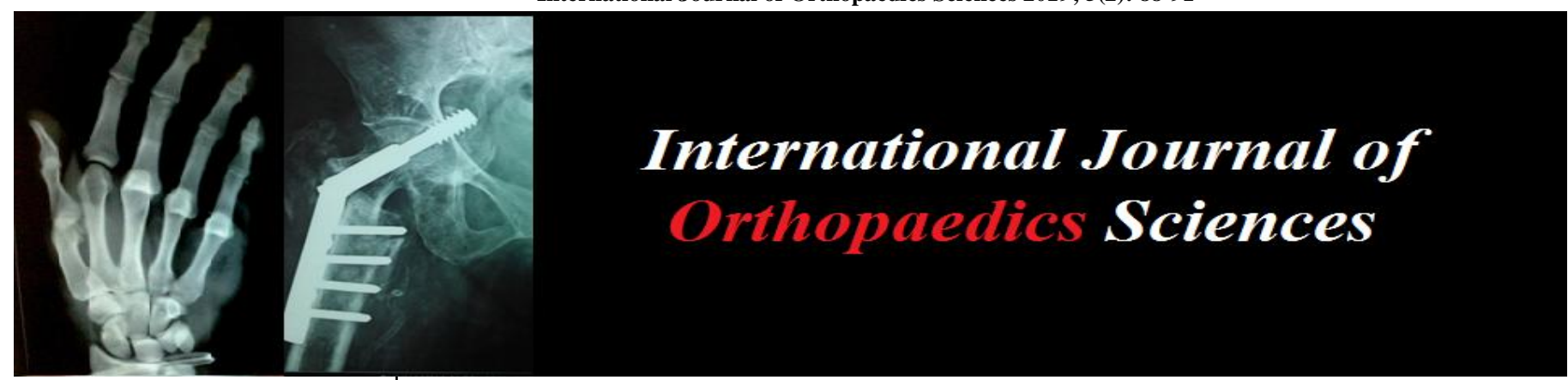

ISSN: $2395-1958$

IJOS 2019; 5(2): 88-91

(C) 2019 IJOS

www.orthopaper.com

Received: 28-02-2019

Accepted: 30-03-2019

Dr. Hareshkumar prabhatbhai Parmar

Designation Assistant

professor, dept. of orthopaedics medical college Baroda,

Vadodara, Gujarat, India

Dr. Vishwash G Sharma

Consultant orthopaedic surgeon,

dept. of orthopaedics medical

college Baroda, Vadodara,

Gujarat, India

\section{Intertrochanter fractures treated with PFNA in patients with age more than 70 years: A study of 42 cases}

\section{Dr. Hareshkumar prabhatbhai Parmar and Dr. Vishwash G Sharma}

DOI: https://doi.org/10.22271/ortho.2019.v5.i2b.20

\section{Abstract}

Intertrochanteric fractures commonly occur in elderly patients. The main aim of surgery is to mobilize the patient early. The most commonly used extramedullary implant is the sliding hip screw while intramedullary implants include the Gamma nail, the intramedullary hip screw, the proximal femoral nail, the ACE trochanteric nail and PFNA (pfn antirotational) designed by AO in 2004. We aim to assess functional and radiological outcome of intertrochanteric fractures treated with PFNA in patients with age more than 70 years. This is a study of 42 fresh intertrochanteric fractures in patients with age more than 70 years where osteosynthesis was done using PFNA during the period of March 2016 to February 2017 at SSG hospital, Vadodara. During follow up clinical and radiological assessment was done. At final follow up functional outcome was assessed using Harris hip score. During follow up 7 patients died due to associated comorbid conditions and 35 patients were available till final follow up. At final follow up according to Harris hip score 27 patients had excellent result, 5 had good result, 2 had fair and one had poor result. PFNA is a good implant in osteoporotic intertrochanteric fractures due to less surgical duration, less blood loss, ease of fixation and low rate of complications.

Keywords: PFNA, Intertrochanter fracture in elderly, Harris hip score

\section{Introduction}

Intertrochanter fractures commonly occur in elderly patients with osteoporosis and its incidence will continue to rise due to the increasing life expectancy. Many methods have been recommended for the treatment of intertrochanteric fractures ${ }^{[1]}$. The main aim of surgery is to mobilize the patient early. It is crucial to use an implant that is minimally invasive, allows early weight bearing and has low complication rates ${ }^{[2,3]}$. Complications associated with pertrochanteric fractures are primarily related to the implant used rather than the union process owing to the strong healing potential of cancellous bone in the intertrochanteric region ${ }^{[4]}$. Surgeon can control fracture reduction, implant selection and implant placement, all of which must be optimized to ensure the success of the surgical intervention. The most commonly used extramedullary implant is the sliding hip screw while intramedullary implants include the Gamma nail, the intramedullary hip screw, the proximal femoral nail, the ACE trochanteric nail and PFNA (PFN Antirotational) designed by AO in $2004^{[5,6]}$.

Although PFN proved to be superior to extramedullary devices for unstable intertrochanteric fractures; screw cut-out, back out, varus collapse and rotational instability continued to be significant postoperative complications, with up to $31 \%$ complication rates being reported in literature ${ }^{[7]}$. The PFNA was designed to achieve better stabilization of the femoral head and neck by using a single helical blade rather than a screw system for fixation. The helical blade is said to increase the bone-implant interface and result in compaction of cancellous bone, thereby providing excellent stability of fixation ${ }^{[8]}$. The blade, which can be inserted without reaming out bone from the head/neck fragment, seems to provide additional anchoring, particularly in osteoporotic bone. Biomechanical studies have proven that the helical blade, by compaction of cancellous bone around it, has superior resistance to rotation and varus collapse ${ }^{[3]}$. We aim to assess functional and radiological outcome of intertrochanteric fractures treated with PFNA in patients with age more than 70 years.
Dr. Hareshkumar prabhatbhai Parmar

Designation Assistant professor, dept. of orthopaedics medical college Baroda, Vadodara, Gujarat, India 


\section{Methods}

This study includes 42 fresh intertrochanteric fractures in patients with age more than 70 years where osteosynthesis done using PFNA during the period of March 2016 to February 2017 at SSG hospital, Vadodara. Patients having other fracture in lower limb, polytrauma patients and pathological fractures were excluded.

All fractures were classified according to AO classification. Data was prospectively collected and analyzed for clinical, radiological and functional results. All patients were operated under spinal anaesthesia. Preoperatively neck shaft angle of opposite side taken and accordingly measured size angle nail was used for fixation. On table reduction was graded according to garden alignment index (GAI) ${ }^{[9,10]}$, Cleveland zones [11] and tip apex distance (TAD) ${ }^{[12]}$ was used to evaluate the placement of helical blade in the femoral head ${ }^{[9]}$. Intra operatively data for reduction of fracture, tip apex distance, size of nail was measured. The length of nail was $240 \mathrm{~mm}$. Single distal locking was done. After first dressing on third postoperative day gradual mobilization of knee and non-weigh bearing exercises were started. All patients were called for follow up 4 weekly till 24 weeks. During follow up clinical and radiological assessment was done. At final follow up functional outcome was assessed using Harris hip score.

\section{Observations and Results}

We have prospectively studied 42 patients of intertrochanteric fractures of age more then 70 years. During follow up 7 patients died due to associated comorbid conditions and 35 patients were available till final follow up. The mean age was 76 years (range 71-88). The female to male ratio was 1.3:1 (20F, 15M). 20 had left while 15 patients had right sided

fracture. 31A2 type was most common fracture pattern. Nine patients had 11A1, 17 had A2 and 9 had A3 type of fracture. The commonest angle of nail size used was 130 degree (Table no.1). In all patients close reduction was done with percutaneus manipulation of fracture fragments when needed. Commonly used blades were between 85-100 mm. In 19 patients reduction was very good according to GAI. In 12 patients reduction was good, in 3 acceptable and in one patient reduction was graded as poor. In 2 patients fixation was in varus. The mean tip apex distance was $16.8 \mathrm{~mm}$ (range $12-26 \mathrm{~mm})$. The commonest size of nail used was $10 \mathrm{~mm} * 240 \mathrm{~mm}$. The mean injury surgery interval was 5.34 days. (Range 3-9 days) The mean hospital stay was 15.54 days (Range 12-20 days). 20 patients had associated comorbid conditions. (Table no. 2) The mean surgical duration in $31 \mathrm{~A}$ was 35 minutes, in 31A2 36 minutes in 31A3 43 minutes. Figure 1 shows good healing of fracture with PFNA.

Table 1: Shows different size of neck shaft angle of nail used.)

\begin{tabular}{|c|c|c|}
\hline Neck shaft angle & No of patients & Percentage \\
\hline 135 & 12 & 34.28 \\
\hline 130 & 20 & 57.14 \\
\hline 125 & 3 & 8.57 \\
\hline
\end{tabular}

Table 2: Shows associated common comorbid conditions in study age group of patients.)

\begin{tabular}{|c|c|c|}
\hline Associated comorbid condition & No of patients & Percentage \\
\hline Hypertension & 9 & 25.71 \\
\hline Ischemic heart disease & 5 & 14.28 \\
\hline Diabites mellitus & 3 & 8.57 \\
\hline Copd & 2 & 5.71 \\
\hline Asthma & 1 & 2.85 \\
\hline
\end{tabular}
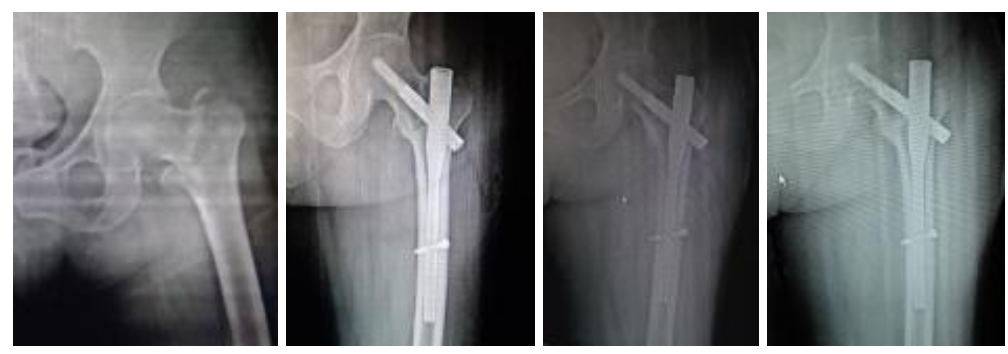

Fig 1: Shows pre-operative, post-operative, follow up and final follow up xry

During follow up one patient had superficial skin infection one had palpable proximal locking blade (Figure 2) and one patient had screw back out. None of the patients had implant failure, cut through of screws. In all patients the fracture was united during follow up. The mean time for fracture union was 13.58 weeks (range 12-20).
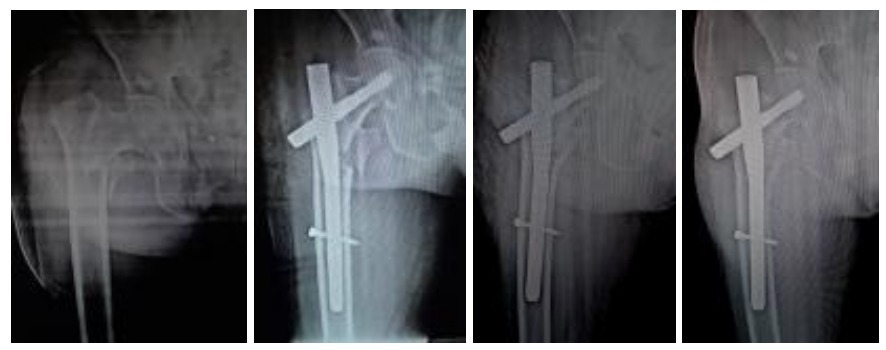

Fig 2: Show preoperative, postoperative, follow up and final follow up xry)

At final follow up 7 patients had slight pain, in four patients on the anterior aspect of thigh and rest had pain at greater trochanteric area. Five patients had slight limp at final follow up. In this study 5 patients required cane for support while walking. Thirty patients were able to walk unlimited distance. Only 5 patients had to use support while climbing. Except for one, all patients were able to enter public transport. Two patients had terminal restriction of flexion, which affected their squatting to some extent, rest had almost full movements. At final follow up according to Harris hip score 27 patients had excellent result, 5 had good result, 2 had fair and one had poor result.

\section{Discussion}

Intertrochanter fractures are usually low velocity injuries in elderly. They commonly occurred from domestic fall. Prevalence of osteoporosis increases in both males and females in geriatric age which can result in fragility fractures like compression fractures in spine, lower end radius fracture and intertrochanter fracture. With increasing age comorbid conditions also rise and fractures of intertrochanter causes loss of mobilization of patients and restrict them to bed.

Previously intertrochanteric fractures were treated conservatively but due to advances in modern orthopedics 
fixation of this fractures provides early mobilization, resulting in decreased morbidity associated with bed ridden patients. Main problems in doing operative intervention in this age group of patients are high risk of anesthesia and associated perioperative mobilization problems. With decreasing the total time for anesthesia and surgical duration the morbidity associated with these fractures can be reduced. PFNA which has single blade and single distal locking provides reduction of time for fixation, c arm exposures and suturing time. Thus overall operative time reduces and total dose of anesthetic agent required for surgery is reduced. This results in less perioperative morbidity. Blade is fixed without so much reaming, causing preservation of natural cancellous bone for union and hammering of blade provides compaction of cancellous bone.

According to literature, the perioperative and postoperative technical complications described in the trochanteric fractures treated with the gamma nail were solved with the development of the PFNA [13-15]. In a study by AguadoMaestro et al., there were 200 patients of pertrochanteric fractures treated with PFNA, they found that helical blade device reduced the rate of cut through and cut out in pertrochanteric fractures and accurate placement of the helical blade was a key factor to prevent mechanical failures and they reported the incidence of cut out was $1 \%{ }^{[16]}$. While the cutout rates were found to be $2 \%$ in a study by Takigami $e t$ al., $4.7 \%$ in a study by Sahin et al. and $7.9 \%$ in a study by Zhang et al. ${ }^{[17-19]}$. The rates of femoral head perforation were found to be $1.4 \%$ in a study by Karapinar et al. and $1.2 \%$ in a study by Simmermacher et al. ${ }^{[20,21]}$

When there is poor reduction of fracture, the vicious cycle starts going in direction of poor implant placement resulting in high failure rate. In the current study reduction was satisfactory in $88.5 \%$ of patients. Ideal TAD was achieved in more than $90 \%$ of patients. Only $2.8 \%$ had implant related complications in this study. The limitations of this study was small sample size, limited age group for selection of patient and less duration of follow up. Large sample size and multicentre study with long follow up protocol may help to produce better outcome variables.

\section{Conclusion}

PFNA is a good implant in osteoporotic intertrochanteric fractures due to less surgical duration, less blood loss, ease of fixation and low rate of complications.

\section{References}

1. Sadic S, Custovic S, Jasarevic M, Fazlic M, Smajic N, Hrustic A et al. Proximal femoral nail antirotation in treatment of fractures of proximal femur. Medical archives. 2014; 68(3):173.

2. Lenich A, Fierlbeck J, Al-Munajjed A, Dendorfer S, Mai R, Füchtmeier B et al. First clinical and biomechanical results of the Trochanteric Fixation Nail (TFN). Technology and Health Care. 2006; 14(4, 5):403-9.

3. Strauss E, Frank J, Lee J, Kummer FJ, Tejwani N. Helical blade versus sliding hip screw for treatment of unstable intertrochanteric hip fractures: a biomechanical evaluation. Injury. 2006; 37(10):984-9.

4. Pu JS, Liu L, Wang GL, Fang Y, Yang TF. Results of the proximal femoral nail anti-rotation (PFNA) in elderly Chinese patients. International orthopaedics. 2009; 33(5):1441-4.

5. Siegmeth AW, Gurusamy K, Parker MJ. Delay to surgery prolongs hospital stay in patients with fractures of the proximal femur. The Journal of bone and joint surgery. British volume. 2005; 87(8):1123-6.

6. Efstathopoulos NE, Nikolaou VS, Lazarettos JT. Intramedullary fixation of intertrochanteric hip fractures: a comparison of two implant designs. International orthopaedics. 2007; 31(1):71-6.

7. Hohendorff B, Meyer P, Menezes D, Meier L, Elke R. Behandlungsergebnisse und Komplikationen nach PFNOsteosynthese. Der Unfallchirurg. 2005; 108(11):938-53.

8. Sharma A, Mahajan A, John B. A comparison of the clinico-radiological outcomes with proximal femoral nail (PFN) and proximal femoral nail antirotation (PFNA) in fixation of unstable intertrochanteric fractures. Journal of clinical and diagnostic research: JCDR. 2017; 11(7):RC05.

9. Lenich A, Mayr E, Rüter A, Möckl C, Füchtmeier B. First results with the trochanter fixation nail (TFN): a report on 120 cases. Archives of orthopaedic and trauma surgery. 2006; 126(10):706-12.

10. Banaszkiewicz PA. Traumatic arthritis of the hip after dislocation and acetabular fractures: treatment by mold arthroplasty: an end-result study using a new method of result evaluation. In Classic Papers in Orthopaedics. Springer, London, 2014, 13-17.

11. Cleveland M, Bosworth DM, Thompson FR, Wilson HJ, Ishizuka T. A ten-year analysis of intertrochanteric fractures of the femur. JBJS. 1959; 41(8):1399-408.

12. Baumgaertner MR, Curtin SL, Lindskog DM, Keggi JM. The value of the tip-apex distance in predicting failure of fixation of peritrochanteric fractures of the hip. JBJS. 1995; 77(7):1058-64.

13. Al-Yassari G, Langstaff RJ, Jones JW, Al-Lami M. The AO/ASIF proximal femoral nail (PFN) for the treatment of unstable trochanteric femoral fracture. Injury. 2002; 33(5):395-9.

14. Herrera A, Domingo L, Calvo A, Martinez A, Cuenca J. A comparative study of trochanteric fractures treated with the Gamma nail or the proximal femoral nail. International orthopaedics. 2002; 26(6):365-9.

15. Albareda J, Laderiga A, Palanca D, Paniagua L, Seral F. Complications and technical problems with the gamma nail. International orthopaedics. 1996; 20(1):47-50.

16. Aguado-Maestro I, Escudero-Marcos R, García-García JM, Alonso-García N, Pérez-Bermejo D, AguadoHernández HJ et al. Results and complications of pertrochanteric hip fractures using an intramedullary nail with a helical blade (proximal femoral nail antirotation) in 200 patients. Revista Española de Cirugía Ortopédica y Traumatología (English Edition). 2013; 57(3):201-7.

17. Zhang H, Zhu X, Pei G, Zeng X, Zhang N, Xu P et al. A retrospective analysis of the Inter Tan nail and proximal femoral nail anti-rotation in the treatment of intertrochanteric fractures in elderly patients with osteoporosis: a minimum follow-up of 3 years. Journal of orthopaedic surgery and research. 2017; 12(1):147.

18. Takigami I, Matsumoto K, Ohara A, Yamanaka K, Naganawa T, Ohashi $\mathrm{M}$ et al. Treatment of trochanteric fractures with the PFNA (proximal femoral nail antirotation) nail system: report of early results. Bulletin of the NYU hospital for joint diseases. 2008; 66(4):276.

19. Şahin EK, Imerci A, Kınık H, Karapınar L, Canbek U, Savran A. Comparison of proximal femoral nail antirotation (PFNA) with AO dynamic condylar screws (DCS) for the treatment for unstable peritrochanteric femoral fractures. European Journal of Orthopaedic 
Surgery \& Traumatology. 2014; 24(3):347-52.

20. Karapinar L, Kumbaraci M, Kaya A, Imerci A, Incesu M. Proximal femoral nail anti-rotation (PFNA) to treat peritrochanteric fractures in elderly patients. European Journal of Orthopaedic Surgery \& Traumatology. 2012; 22(3):237-43.

21. Simmermacher RK, Ljungqvist J, Bail H, Hockertz T, Vochteloo AJ, Ochs U et al. The new proximal femoral nail antirotation (PFNA®) in daily practice: results of a multicentre clinical study. Injury. 2008; 39(8):932-9. 